\title{
Current concepts regarding the HTLV-1 receptor complex
}

\author{
David Ghez ${ }^{1,2^{*}}$, Yves Lepelletier ${ }^{1}$, Kathryn S Jones ${ }^{3}$, Claudine Pique ${ }^{4,5}$, Olivier Hermine ${ }^{1,6^{*}}$
}

\begin{abstract}
The identity of the Human T lymphotropic Virus type 1 (HTLV-1) receptor remained an unsolved puzzle for two decades, until the recent demonstration that three molecules, Glucose Transporter 1, Neuropilin-1 and Heparan Sulfate Proteoglycans are involved in HTLV-1 binding and entry. Despite these advances, several questions remain unanswered, including the precise role of each of these molecules during virus entry. In light of the most recent data, we propose a model of the HTLV-1 receptor complex and discuss its potential impact on HTLV-1 infection.
\end{abstract}

\section{Introduction}

Since its identification in 1979, the Human T-Lymphotropic Virus type 1 (HTLV-1) has been the subject of extensive research. Despite abundant experimental data, several unsolved mysteries still surround HTLV-1. Amongst those, the identity of the HTLV-1 cellular receptor has eluded scientists for over two decades. Since 2003, data from several independent groups have shed light on the identity of the molecules that appear to be directly involved in the process of HTLV-1 entry. These include Glucose Transporter 1 (GLUT1) $[1,2]$, Neuropilin-1 (NRP-1) [3-5] and Heparan Sulfate Proteoglycans (HSPG) [6,7]. Despite these advances, our current knowledge of their precise roles during HTLV-1 entry remains limited. In particular, little is known about interaction between these molecules, including whether they form a multimolecular complex similar to that of the well-studied Human Immunodeficiency Virus type 1 (HIV-1) receptor. In this review, we will summarize the data pertaining to HTLV-1 entry molecules, propose a hypothetical model of the HTLV-1 receptor and discuss its possible impact on the pathobiology of HTLV-1 infection.

\section{The HTLV-1 Receptor Enigma HTLV-1 entry}

It is widely believed that HTLV-1 enters cells in a manner similar to that of other retroviruses including the

\footnotetext{
* Correspondence: david.ghez@igr.fr; ohermine@gmail.com

'CNRS UMR8147, Universite Rene Descartes, Paris 5, 161 Rue de Sèvres, 75743 Paris Cedex 15, France

Full list of author information is available at the end of the article
}

well-studied HIV-1. HTLV-1 infection of target cells is believed to require the two virally encoded envelope glycoproteins (Env), the surface subunit (SU) gp46 and the transmembrane subunit (TM) gp21, generated from the cleavage of a polyprecursor (gp61) in the Golgi apparatus [8]. As has previously been shown for the SU (gp120) and TM (gp41) of HIV-1 [9], the SU and TM of HTLV-1 are believed to function successively during the entry process. The gp46/SU, which does not contain a transmembrane region, is tethered to the cell surface through interactions with the gp21, and is involved in direct interactions with the cell surface receptors. Like the HIV-1 gp41, the gp21 of HTLV-1 contains a transmembrane region and a $\mathrm{N}$-terminal hydrophobic fusion peptide that plays a crucial role in the fusion of the viral and cellular membrane during the final steps of HTLV1 entry [10,11]. Earlier work showed that both the presence of certain mutations in the env gene and antibodies directed against gp46/SU partially or totally abolished HTLV-1 infection in vitro [12,13]. Infection was also reduced by exposure of target cells to a soluble recombinant protein containing soluble full-length SU, indicating that it could compete with the SU on the surface of the virus for the binding to yet unknown molecules at the cell surface [14]. Altogether, these experiments confirmed that the two Env glycoproteins play crucial role during HTLV-1 entry and indicated that, as for other retroviruses, this process depends on the expression of cellular receptor(s) at the surface of target cells. Interaction between gp46/SU and its cellular receptor(s) induces a conformational change that 
unmasks the fusion domain within the TM, allowing fusion between the viral and cellular membranes [15].

\section{The search for the HTLV receptor}

Experimental demonstration that specific molecules function as a virus receptor often is a challenge [16]. This is illustrated by the fact that there are a great number of viruses, including certain retroviruses, for which no receptors have been identified. In addition, for certain viruses, it has been shown that more than one molecule may function as entry receptors. Some viruses use different receptors on different cell types, while others require the presence of both molecules on a given target cell to facilitate entry. In the case of HTLV1 , several peculiar features of the virus and its receptor (s) have considerably hampered research. First, free HTLV-1 virions are poorly infectious for most cell types and efficient infection of $\mathrm{T}$ cells requires a cellular contact [17]. Secondly, infected lymphocytes produce a limited amount of viral particles, amongst which 1 out of $10^{5}$ are actually infectious [18]. Lastly, the fact that molecules capable of binding and allowing HTLV-1 entry are expressed on nearly all available established cell lines has prevented the use of classical strategies such as the screening of a cDNA bank in receptor-negative cells.

\section{In vivo versus in vitro entry tropism: the paradox of the HTLV-1 receptor}

Virus tropism, the ability of a virus to replicate in particular cells, depends on interactions between viral components and cellular factors at each step of the viral cycle from the initial entry to the ultimate release and transmission of virions. Here, we will focus on the cellular factors that allow HTLV-1 entry, which is determined by the distribution of the receptor molecule(s).

\section{In vivo entry tropism}

Although the main targets of HTLV-1 are $\mathrm{CD} 4^{+} \mathrm{T}$ cells [19], the virus has been found in other cell types in vivo including as $\mathrm{CD}^{+} \mathrm{T}$ cells [20], monocytes and B cells [21], macrophages [22], dendritic cells (DC) [23,24] and endothelial cells [25]. In vivo, the only known targets of virus-induced transformation are $\mathrm{CD}^{+}{ }^{+} \mathrm{CD}_{4} 5 \mathrm{RO}^{+}$memory $\mathrm{T}$ cells [26]. Recently, it has been hypothesized that natural regulatory $\mathrm{T}$ cells (Tregs) can be infected. This was based on the fact that HTLV-1 infected T cells and Tregs have a strikingly close phenotype: CD25+, (which is a direct consequence of HTLV-1 Tax synthesis [27]), GITR+ and FoxP3+ $[28,29]$. If true, this could partly explain the frequent immune dysregulation observed in HTLV-1-infected individuals. However, studies from other laboratories suggest that Tregs are not infected by the virus $[30,31]$. This is consistent with other work showing potent suppressive activity of HTLV-1-infected or transformed T cells in only a portion of HTLV-1infected patients $[32,33]$. This could be due to the impairment of FoxP3 function by the HTLV-1 Tax protein, as shown by Jacobson's group [34]. In contrast, it has been suggested that HTLV-1 may have an indirect effect on Tregs since Bangham's group recently reported that the frequency of uninfected functional Tregs is abnormally high in HTLV-1-infected individuals [35], which may account as well for the immunosuppression associated with HTLV-1 infection.

\section{In vitro entry tropism}

In striking contrast to the limited number of cell-types in which HTLV-1 is detected in vivo, molecules capable of supporting the initial steps in infection, binding and entry, appear to be expressed on nearly all established cell lines. As discussed below, this is consistent with the fact that molecules in the receptor complex are up-regulated on most transformed cells. Moreover, the HTLV-1 receptor complex is present on cell lines from nearly all known vertebrate species [36]: most available established cell lines are able to form multinucleated giant cells (syncytia) when cultured with Env expressing cells, a phenomenon that is dependent on Env/Receptor interactions [37]. Further evidence that HTLV-1 receptors are widely distributed comes from observations that HTLV-1 Env-pseudotyped particles can infect a number of established cell lines [38]. More recently, binding studies with soluble, full-length HTLV-1 SU (SU-Fc) has not only confirmed the results obtained with infection and fusion experiments but also showed that a wider range of established cell lines expressed molecules capable of specifically binding the SU protein [1]. Work from the Brighty laboratory found that the SU-Fc protein could bind to a vast number of vertebrate cell lines including some that were originally thought to be receptor negative due to their resistance to Env-mediated cell to cell fusion or infection [39]. This study identified one cell line, the drosophila cell line S2, that lacked molecules capable of specifically binding HTLV SU on the cell surface. Unfortunately, these cells could not be used to identify HTLV-1 receptors, since they have post-entry blocks to HTLV-1 and other retroviruses.

\section{Properties of the HTLV-1 receptor: indirect evidence}

Although its ubiquitous nature considerably complicated its identification, several properties of the HTLV-1 receptor, in particular its expression pattern on primary cells, were characterized using indirect approaches. In 2003, two independent groups generated soluble SU proteins by generating recombinant SU-Ig-Fc fusion proteins containing either the full-length SU [22] or the $\mathrm{N}$-terminal portion of SU (Receptor Binding Domain, see section 3.1) [40]. Their findings showed that the receptor was not present at the surface of resting $\mathrm{CD} 4^{+}$ 
$\mathrm{T}$ cells but was rapidly upregulated upon activation. The receptor was also absent on naive $\mathrm{T}$ cells isolated from cord blood but could similarly be upregulated after stimulation by interleukin-7. Finally, it was reported that the SU-Fc could inhibit a mixed lymphocyte reaction [22]. This last property suggested that one of the molecules involved in the HTLV-1 receptor was a member of the immune synapse. Surface expression of the receptor was found to be not solely dependent on $\mathrm{T}$ cell activation. It could also be upregulated upon exposure to TGF- $\beta$, a potent negative regulator of the immune response [41]. The pattern of surface expression following exposure to TGF- $\beta$, as determined from binding of the soluble SU, was very similar to that observed after activation with PHA/IL-2, although with slightly slower kinetics. It depended on the TGF- $\beta$ classical signalling pathway as it was abolished in the presence of Smad inhibitors. TGF- $\beta$ not only triggered receptor expression at the cell surface but also increased the titer of lentiviral vectors pseudotyped with HTLV-1 Env in vitro, demonstrating that molecules capable of both binding and fusion were expressed [41]. TGF- $\beta$-treated T cells remained in a resting state, demonstrating that $\mathrm{T}$ cell activation per se was not required for receptor expression. This might constitute a strategy for the virus to increase its infectivity [42] as HTLV-1-infected CD4 ${ }^{+} \mathrm{T}$ cells are known to abundantly secrete TGF- $\beta$.

\section{Candidate receptors whose role was ruled out}

Over the years, several molecules were proposed as candidate HTLV-1 receptors. It was proposed that the HTLV-1 receptor is encoded by chromosome 17q23.2-23.5, which was questioned in later studies $[38,43]$. Most of the candidate receptors were identified as antigens against which specific antibodies could inhibit Env-mediated cell fusion [43-46]. It was later shown that some antibodies may inhibit this process through non-specific protein crowding, rather than directly competing for binding, making the results difficult to interpret [47]. Adhesion molecules, which strengthen and stabilize the cell-to-cell contact, can also augment cell fusion in a non-specific manner [48]. Most importantly, none of these molecules had demonstrated one fundamental property of the receptor, that is, the ability to bind the HTLV-1 SU. In contrast, as it could bind the 197-216 region of the $\mathrm{SU}$, the heat shock cognate protein HSC70 was proposed as a receptor [49]. However, later studies showed that, while HSC70 modulates HTLV1 -induced syncytia formation, it was dispensable for HTLV-1 infection [50], ruling out that this molecule was an entry receptor. The tetraspanin CD82 was also shown to bind the HTLV-1 Env protein but was excluded as an entry receptor on the fact that its overexpression inhibited, rather than enhanced, syncytia formation and HTLV-1 transmission [51].

\section{Not one but Three Receptor Molecules: GLUT1, HSPG and NRP-1}

\section{The glucose transporter GLUT1}

It was not until 2003 that work from Sitbon and Battini's laboratory identified a candidate that matched all the prerequisites to be a HTLV-1 receptor [2]. Furthermore, this group determined that this molecule interacted with both HTLV-1 and the related virus HTLV-2, believed to use a common entry receptor. After noticing that overexpression of either the HTLV-1 or HTLV-2 Env in cells prevented acidification of the culture medium, the authors hypothesized that the HTLV-1 receptor might be related to the proton-dependent lactate production. Based on their previous identification of the receptor binding domain (RBD) of HTLV-1 or HTLV-2, these authors further reported that the overexpression of either the H1-RBD (first 215 residues of the HTLV-1 $\mathrm{SU}$ ) or the H2-RBD (178 residues of the HTLV-2) $[40,52,53]$ altered glucose metabolism, which was consistent with the frequent use of metabolite transporters as entry receptors by retroviruses [16]. They focused on the ubiquitous glucose transporter 1 (GLUT1), which is upregulated in activated $\mathrm{T}$ cells, and found that overexpression of GLUT-1 in cells increased the level of binding of both the H1- or H2-RBD. In the absence of available GLUT1-negative cell lines, they used different approaches, in particular small interfering RNA (siRNA), to demonstrate that GLUT1 played a role in HTLV-1 entry. Down regulation of GLUT1 by siRNA both inhibited the binding of the H1- or H2-RBD and infection by retroviral vectors pseudotyped with either the HTLV-1 or -2 Env. Both were restored after cotransfection of GLUT1 but not GLUT3, a related glucose transporter. They later extended their findings by that identifying a specific residue in the HTLV-1 SU (Y114) of the H1RBD that appeared critical to the interaction [52], which interacted with the $6^{\text {th }}$ extracellular loop (ECL6) of GLUT1 [54].

Further data from other laboratories confirmed that GLUT1 plays a role in HTLV-1 entry. TGF- $\beta$, which had previously been shown to upregulate molecules capable of binding HTLV SU, induces GLUT1 at the surface of T cells [41]. Overexpression of GLUT1 in the bovine MDBK cell line, which is relatively resistant to HTLV-1 infection, increases two-fold the infectious titre of a HTLV-1 Env pseudotyped lentivirus vector [55]. A similar result was obtained in the NIH3T3 cell line, which is also poorly susceptible to infection by HTLV-1 pseudotyped vectors [1]. Antibodies raised against GLUT1 ECL1 (GLUT-IgY) block both Env-mediated fusion and infection. Furthermore, blocking interactions with GLUT1 ECL1, either by replacing the GLUT1 ECL1 with that of GLUT3, or by blocking with ECL1derived peptides, inhibits HTLV-1-induced cell fusion, 
suggesting that ECL1 is critical for the receptor activity of GLUT1 [1]. This confirmed earlier data showing that, although only the ECL6 was required for the binding of the H1-RBD to GLUT1, infection by HTLV-2-pseudotyped viruses also required residues located in ECL1 and ECL5 of this molecule [54]. This indicates that GLUT1 contains multiple functional determinants: those required for interactions with the RBD portion of the HTLV SU, located in ECL6, and others required for interactions of the entire Env, consisting of the fulllength SU protein and the TM protein, located in ECL1 and ECL5. Thus, current data indicate that GLUT1 plays a role in HTLV-1 entry.

However, several studies suggested that the identification of GLUT1 was not the end of the story. The astrocytoma/glioblastoma U87 cell line, which expresses very low levels of GLUT-1 due to a transdominant negative mutation in one of the alleles of GLUT1 (GLUT-1 D5), is easily infected by HTLV-pseudotyped viruses[3,56]. Moreover, blocking interactions with GLUT1 by either siRNA-mediated down-regulation, or by incubating with GLUT-IgY blocking antibodies, has no effect on the level of infection with HTLV-Env-pseudotyped virus or HTLV Env-mediated fusion or infection in this cell line, suggesting that molecules other than GLUT1 might be involved [56]. An earlier study reported that overexpression of GLUT1 in a cell line (COS-7) increased cell-cell transmission, but did not increase the level of binding of the SU-Fc protein [57]. Similarly, more recent studies using clones of the U87 cell line that express different levels of GLUT1 have observed that the level of cell surface GLUT1 correlates with the titer of HTLV-1 Env pseudotyped viruses, but not with SU-Fc binding [58]. All these findings suggested that molecules other than GLUT1 are also involved in HTLV-1 entry, especially at the binding step.

\section{Heparan Sulfate Proteoglycans modulate HTLV-1 attachment and entry}

Molecules of the HSPG family are composed of a core protein associated with one or more sulphated polysaccharide side chains called heparan sulfate glycosaminoglycans. Because of their highly negative charge, HSPG bind through electrostatic interactions to a plethora of proteins including growth factors and their receptors, chemokines, cytokines and numerous proteins of the extracellular matrix or the plasma, thereby playing a major role in mammalian physiology [59]. Pathogens, including many viruses, have been shown to hijack HSPG [60]. HSPG generally enhance infection by facilitating the attachment of the particles on target cells and/or allowing their clustering at the cell surface before specific interactions between viral proteins and their receptors that lead to fusion. For example, prior to interaction of the HIV SU (gp120) with CD4, the initial attachment of the virus to target cells involves specific interactions between gp120 and cellular HSPG [61]. Rarely, a specific role of HSPG in the fusion process has been observed, in particular with Herpes Simplex virus [62].

The important role of HSPG in mediating attachment and entry has also been demonstrated for HTLV-1. Enzymatic removal of HSPG or inhibition of electrostatic interactions with dextran sulfate decreases the binding of full length soluble SU, Env-mediated syncytium formation and infection with pseudotyped viruses [7]. These initial findings, obtained in non-lymphoid cell lines expressing high levels of HSPG, were later confirmed in $\mathrm{CD}^{+} \mathrm{T}$ cells in Jones and Ruscetti's laboratory [6]. Although HSPG are barely detectable on quiescent $T$ cells [63], they are rapidly upregulated upon activation. In $\mathrm{CD} 4^{+} \mathrm{T}$ cells, HSPG augment both the binding of the SU-Fc and the infectious titer of pseudotyped viruses [6]. The importance of HSPG was suggested by studies showing that removing HSPG reduced binding and entry of HTLV-1 virus into CD4+ T cells and dendritic cells $[4,6]$ and significantly reduced the level of HTLV-1 infection.

Other recent studies suggest another role for HSPG during cell-cell transmission of the virus. It was discovered that HTLV-1 virions are stored outside the cell, within a protective microenvironment enriched for specific components of the extracellular matrix, including lectins and HSPGs [64]. Following contact between T cells, these structures are rapidly transferred from infected to uninfected cells, ultimately resulting in infection of the target cell. This suggests that HSPG could play a broader role in HTLV-1 transmission by facilitating both the transfer of newly-formed virions from an infected $\mathrm{T}$ cells and the subsequent entry into the target $\mathrm{T}$ cell. The galactose-binding lectin Galactin-1, which has been shown to increase HTLV-1-Env mediated infection [65], might also have a similar function.

Interestingly, HSPG are important for infection with HTLV-1 but not HTLV-2 [66], showing that these two viruses, initially considered to share the same receptor [67], may share some but not all molecular determinants for entry. It has previously been reported that HTLV-1 SU has the ability to bind HSPG; this ability maps to the C-terminal region of HTLV-1 SU, located downstream the RBD and the proline rich region [66]. Interestingly, the Green laboratory has previously reported that the preferential tropism of HTLV-1 and HTLV-2 to transform $\mathrm{CD}^{+}{ }^{+} \mathrm{T}$ cells or $\mathrm{CD} 8^{+} \mathrm{T}$ cells, respectively, is governed by Env [68]. The difference in the requirement of HTLV-1 and HTLV-2 two SU for HSPG might explain the different tropisms of the two retroviruses. Indeed, $\mathrm{CD}_{4}^{+} \mathrm{T}$ cells express a high level of HSPG and 
a lower level of GLUT1 whereas $\mathrm{CD}^{+} \mathrm{T}$ cells express a high level of GLUT1 but very few HSPG. In this model, the differences between HTLV-1 and HTLV-2 would be similar to what has been described in CD4-dependent and independent HIV-2 or SIV strains, which differ in their requirements for the binding receptor (CD4) but share similar fusion receptors [69].

\section{The third player: Neuropilin-1}

In 2006, the Hermine and Pique laboratories showed that Neuropilin-1 (NRP-1) also displayed properties expected for a HTLV-1 receptor [5]. This hypothesis was confirmed in a recent study [3]. NRP-1 is a 130 $\mathrm{kDa}$ single membrane spanning glycoprotein which acts as the co-receptor for Semaphorin 3a and VEGFA 165 . NRP-1 was initially identified as a critically important factor in embryonic neuron guidance, and later shown to be a key player in the regulation of angiogenesis. In addition, Romeo and Hermine's laboratories were the first to demonstrate that NRP-1 is also involved in the regulation of the immune response [70]. NRP-1 is highly conserved amongst vertebrate species but there are no NRP-1 homologs in insects [71]. NRP-1 is mainly expressed in $\mathrm{T}$ cells and $\mathrm{DC}$, which are targets of HTLV-1 in vivo. NRP-1 is highly expressed on plasmacytoid DC (pDC), which can be infected by cell-free virus in vitro [72]. Endothelial cells, in which HTLV-1 proviral DNA has been detected in vivo [25], also express NRP-1 [73]. NRP-1 is absent on resting T cells but is rapidly upregulated following activation [72,74]. In contrast with its relatively limited expression in vivo, NRP-1 is found in many tumor cells [73] and hence is expressed on an extremely broad range of established cell lines. Finally, NRP-1 plays a role in cytoskeletal rearrangement, a phenomenon that has been shown to be important for transmission of different retroviruses including HTLV-1 [75].

Ghez et al. reported that NRP-1 was able to directly interact with the HTLV-1 and -2 SU [5]. This interaction appeared functionally relevant since NRP-1 overexpression enhanced syncytium formation and the titer of HTLV-1 or -2 Env pseudotyped viruses whereas siRNAmediated NRP-1 downmodulation had the opposite effect [5]. A strong polarization of NRP-1 and Env on either side of the interface between an infected cell and a target $\mathrm{T}$ cell was observed using confocal microscopy. This phenomenon was also observed with GLUT1, though GLUT1 was also found to colocalize at the membrane junction of two uninfected T cells, thus in an Env-independent manner. Both polarization and colocalization of the three molecules were particularly intense at regions where partial membrane fusion was taking place. It was also observed that GLUT1 and NRP-1 could form intracytoplasmic complexes in transfected cells, an association that was greatly enhanced in the presence of Env [5].

\section{A new understanding of HTLV-1 tropism}

The identification of three new molecules involved in the process of HTLV-1 entry allows one to revisit the HTLV-1 tropism paradox mentioned above. While HSPG usage appears to distinguish HTLV-1 and HTLV2 , their ubiquitous expression cannot explain the limited tropism of HTLV-1 in vivo. This is also the case of GLUT1, whose expression is ubiquitous as well. In contrast, the distinct pattern of NRP-1 expression in vivo and in vitro may explain the disparity between the in vivo and in vitro tropisms. In primary cells, NRP-1 is mainly expressed on endothelial cells, activated $\mathrm{CD}^{+}{ }^{+} \mathrm{T}$ cells and DC, all of which have been observed to be infected in vivo. However, NRP-1 overexpression upon cell transformation renders it nearly ubiquitous among established cell lines. Moreover, the $n r p-1$ gene is strongly conserved between mammalian species and has no homolog in insects. These findings strongly favor the notion that the in vivo HTLV-1 tropism is mainly dictated by NRP-1 expression.

\section{At Last, Several Receptors or a Receptor Complex?}

Thus, after more than 20 years, three different molecules have proven to be important for HTLV-1 entry. It seems clear that HSPG, as for nearly all other viruses, is involved in binding but not in fusion. The properties displayed by both GLUT1 and NRP-1, i.e. binding to the HTLV-1 SU and modulation of infection, are consistent with those expected for a receptor but, as mentioned above, many questions on their exact function remain unsolved. In particular, it is not clear whether GLUT1 and NRP-1 cooperate to promote HTLV-1 entry. We will review very recent data that have started to clarify the respective roles of $\mathrm{HSPG}, \mathrm{NRP}-1$ and GLUT1 in HTLV-1 infection.

\section{GLUT1 and NRP-1 bind distinct regions of the HTLV-1 SU}

As was hypothesized previously, there is now definitive evidence that GLUT1 and NRP-1 bind to distinct regions of SU. Kim et al. determined that the minimal RBD is located within the first 183 amino terminal residues of the HTLV-1 SU [52]. Mutation of the tyrosine residue 114 completely abolished the binding of $\mathrm{H} 1$ $\mathrm{RBD}$, suggesting it plays a critical role. However, the results of binding studies using RBD should be interpreted with caution, as they might not truly represent what occurs with the full length SU or the SU/TM complex in the native Env. Several lines of evidence suggest that this may be the case. For example, over expression of GLUT1 strongly increased binding of the H1-RBD 
[2], but has little impact on the binding of full-length HTLV-1 SU [57]. It is thus possible that shortening the SU modifies its quaternary structure and mimics a conformational change resulting in an "active" form capable of binding directly to GLUT1, possibly by exposing the tyrosine residue 114 [52]. It is tempting to speculate that the conformational change allowing the association to GLUT1 might be dependent on the initial SU binding to NRP-1. This would be analogous to what occurs for HIV, where SU (gp120) binding to CD4 induces a conformational change that allows binding to the co receptors, which facilitates fusion.

The HSPG-interacting SU region is located outside the GLUT1 and NRP-1 binding sites, and thus should not decrease its affinity to the other two molecules; this interpretation is consistent with the data showing that increasing cell surface levels of HSPG increases SU binding to receptor-expressing cells [6,7]. Blocking the ability of SU to interact with HSPG, either by enzymatic removal or incubation with a peptide mimicking the HSPG-binding domain of VEGFA 165 (exon-7 peptide), decreased the DC-mediated transfer of HTLV-1 to CD4 $+\mathrm{T}$ cells by $50 \%$. Moreover, blocking both HSPG and NRP-1 interactions decreased HTLV-1 infection by $80 \%$ $[4,72]$. Thus, HSPG are important for the efficiency of HTLV-1 infection, likely by increasing and stabilizing the initial SU binding to NRP-1, a phenomenon already described for gp120 and CD4 [76].

In 2009, Lambert et al. found that the binding of the HTLV-1 SU to NRP-1 involved two distinct types of interaction: an indirect interaction mediated by HSPG and a direct interaction mediated by the amino-acids 90-94 of the SU [4]. Moreover, they identified a region of SU (aa 90-94) that is homologous in both sequence and function to the exon 8 domain of the NRP-1 ligand VEGFA $_{165}$, [77]. This demonstrates that the SU binds to NRP-1 using molecular mimicry of VEGFA ${ }_{165}$. Interestingly, the aa 90-94 motif is conserved in the SU proteins of HTLV-2, HTLV-3 and related Simian T-Lymphotropic Viruses but not other retroviruses [4] and is the target of neutralizing antibodies [78]. Strikingly, Kim et al. showed that mutating either aa $94(\mathrm{R})$ or $114(\mathrm{Y})$, which inhibits direct interaction with NRP-1 or GLUT1 respectively, is equally efficient in preventing interference due to overexpression of the H1-RBD in target cells [52]. This reinforces the notion that the direct interaction of SU with both NRP-1 and GLUT1 is required for HTLV-1 entry.

\section{Towards a hypothetical model of the HTLV-1 receptor}

In light of these data, it is possible to draw a model for HTLV-1 entry based on an analogy with HIV CD4/ CXCR4 or CCR5 receptor complexes, and what is known about interactions of NRP-1 with its ligand
VEGFA $_{165}$, HSPG, and receptor (Figure 1). During the initial binding phase, the SU would interact with HSPG via its $\mathrm{C}$-terminal portion, allowing its attachment to the cell surface (Figure 1, step 1). This would enhance the local concentration of SU, and thus increase the probability of interactions with NRP-1. This notion is consistent with observations that removal of cell surface HSPG dramatically reduces the level of binding of the $\mathrm{SU}$ or virions to $\mathrm{CD} 4^{+} \mathrm{T}$ cells [6], the titer of pseudotyped virus, and the infection of $\mathrm{CD}^{+} \mathrm{T}$ cells and $\mathrm{DC}$. HSPG/SU complexes would then interact with the $b$ domain of NRP-1, through both HSPG/NRP-1 interactions and direct SU/NRP-1 binding mediated by the 9094 region of the SU (step 2). This binding to NRP-1 could trigger a conformational change within the $\mathrm{SU}$, exposing the region necessary for GLUT1 binding including the critical Y114. Finally, the interaction of the SU with GLUT1 could trigger the fusion process necessary to HTLV-1 entry (step 3). In this model, NRP1, with the help of HSPG, is the primary binding receptor, while GLUT1 is the fusion receptor. This is consistent with the formation of NRP-1/Env/GLUT1 complexes and with the fact that GLUT1 over expression does not increase the level of HTLV-1 SU binding. This model applies to both primary $\mathrm{CD} 4^{+} \mathrm{T}$ cells and $\mathrm{DC}[4,72]$. Recent data showing that HTLV-1 entry into primary astrocytes requires both NRP-1 and GLUT1 [3] suggest that this view is true for these cells as well.

Whether this model is relevant for HTLV-1 entry in other types of cells remains to be investigated. A recent paper from Alkhatib's group showed that GLUT1, but not NRP-1, was involved in HTLV-1 entry into Hela cells [3]. Moreover, the same group was the first to show that HTLV-1 can efficiently enter into U87 cells, in which the surface level of GLUT1 is very low [56]. Low level of GLUT1 at the cell surface could be sufficient to promote fusion if the density of surface NRP1 is high, which is the case of the U87 cell line [3]. Indeed, it was shown that $\mathrm{T}$ cells expressing very low levels of CCR5 but high levels of CD4 were still competent for HIV envelope-mediated membrane fusion [79]. Alternatively, NRP-1 could function on certain cell types as both the binding and fusion receptor, as suggested for $\mathrm{CHO}$ cells [3]. Finally, one cannot exclude the possibility that, like HIV, HTLV-1 uses different fusion receptors on different cell types and other unidentified molecules could serve as fusion receptors for HTLV-1.

Other evidence supporting a NRP-1/GLUT1- complex comes from reports that a small intracytoplasmic protein called GLUT1CBP or PSD-95/Dlg/ZO- 1 can bind both NRP-1 and GLUT1 via its PDZ domain [80,81]. Moreover, syndecans, the main members of the HSPG family, also contain a PDZ-binding motif at their Cterminus of their cytoplasmic domain [82]. Deletion of 


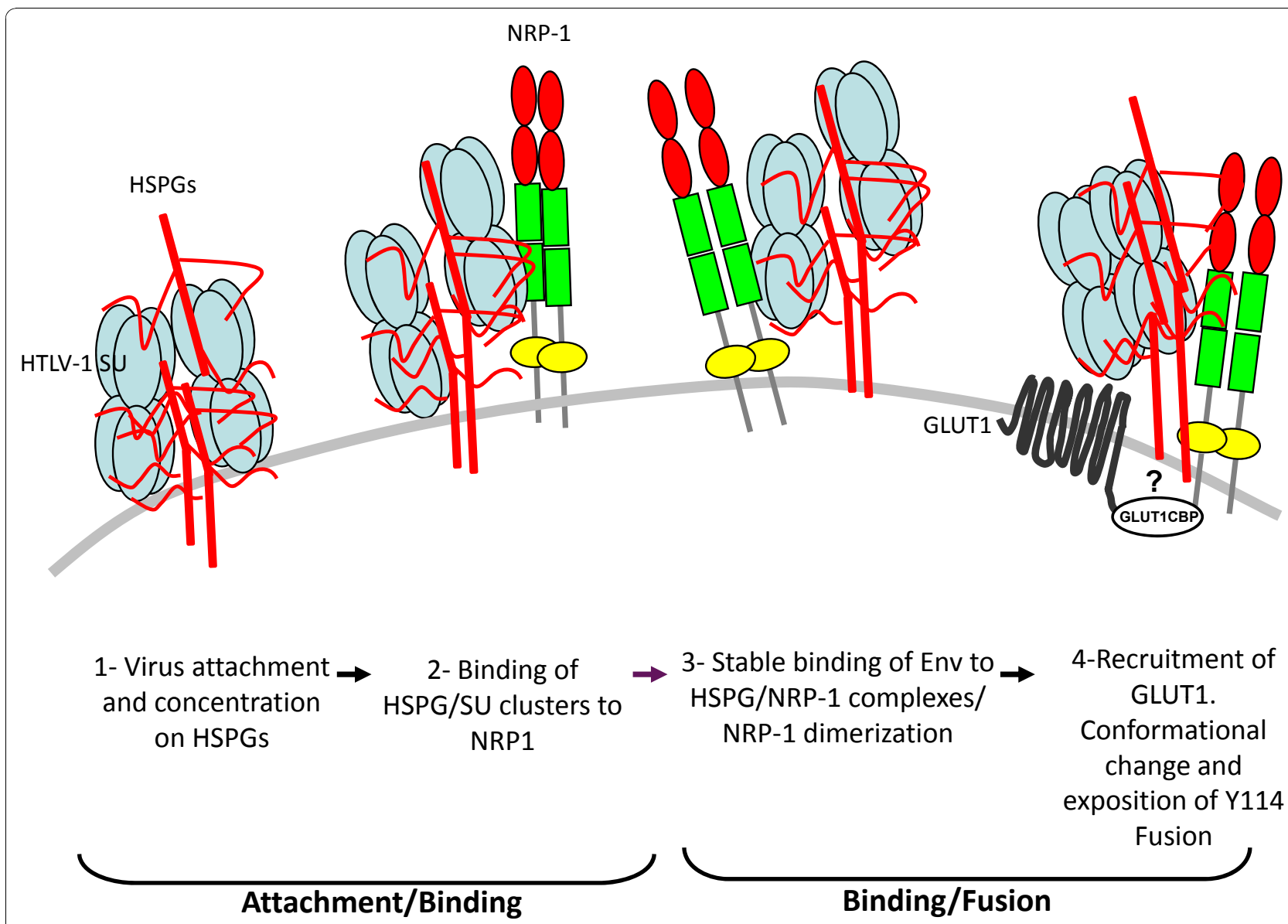

Figure 1 Hypothetical model of the HTLV receptor complex and HTLV entry: 1- HSPG interaction with the SU allow the initial attachment and concentration of the virions at the cell surface. 2- HSPG facilitates the recruitment of the SU to NRP-1. 3- Using molecular mimicry of VEGFA $_{165}$, the SU region 90-94 interacts with the b domain of NRP-1, an interaction that is stabilized by HSPG. 4- SU-NRP-1 interaction triggers a conformational change within the SU, allowing exposure of the tyrosine 114 that is critical for binding to GLUT1. Interaction between GLUT1 and the SU triggers a conformational change allowing the unmasking of the TM fusion peptide (not depicted). The small adaptor protein GLUT1CBP might form a link between NRP1 and GLUT1 and stabilize the receptor complex.

the PDZ-binding motif of GLUT1 was shown to preclude GLUT1 clustering at the plasma membrane [83]. GLUT1CBP could therefore act as a "bridge" to stabilize the entire tripartite receptor complex. It could also provide cues for cytoskeletal polarisation, since it can associate with several cytoskeletal proteins [80] (Figure 1 , step 3). Altogether, this model not only reconciles nearly all of the recent data obtained on the HTLV-1 receptor but also appears to explain the in vivo tropism of the virus better than the GLUT1-only hypothesis.

\section{Perspectives}

Given its role in the immune system, the discovery of NRP-1 as an entry molecule for HTLV-1 opens interesting perspectives on viral transmission and the physiology of HTLV-1 related diseases.

\section{Targeting dendritic cells and disturbing the immune} response

Plasmacytoid DC (pDC), and to a lesser extent myeloid dendritic cells (myDC), constitutively express high levels of NRP-1, which is involved in the regulation of DC-T cell interactions at the immune synapse [70]. Shaking the commonly accepted idea that HTLV-1 could only be transmitted via cell to cell contact, it was recently found that free HTLV-1 virions could efficiently infect DC [72]. The contact of HTLV-1-infected DC with CD4 ${ }^{+} \mathrm{T}$ cells upregulates NRP-1 and HSPG within an hour followed by transmission of HTLV-1 to T cells and productive infection. This phenomenon appears to be dependent on both NRP-1 and HSPG expression on the target $T$ cells [72]. Viral transmission may occur in cis (from virus produced from infected DCs) but also in 
trans (prior to infection of the DC), as has been previously shown for DC-mediated HIV infection. This raises the question of whether $\mathrm{DC}$ (in particular pDC) could constitute a reservoir for the virus. Several laboratories have reported detecting HTLV-1 sequences in DC in vivo [84]. It would be interesting to determine whether, in contrast to $\mathrm{T}$ cells, an active replication cycle takes place in $\mathrm{pDC}$ in vivo.

Targeting DC and interfering with NRP-1 signalling might have several other consequences on viral infection. HTLV-1 infection results in a depletion of myDC as well as pDC and an impairment of their IFN $\alpha$-producing capacity [85]. Furthermore, the number of pDC is negatively correlated to the proviral load, suggesting a certain degree of impairment of the antiviral response. It is still not known whether this pDC decrease is due to true depletion or, as in HIV infection, to their migration into lymphoid tissues. Recent in vitro data demonstrated that cell-free HTLV-1 generates a pDC innate immune response by an induction of costimulatory molecules, production of massive levels of IFN- $\alpha$, and rapid expression of the apoptotic ligand TRAIL. The role of NRP-1 in this process remains to be clarified. Furthermore, HTLV-1-stimulated pDC was shown to induce apoptosis of $\mathrm{CD}^{+} \mathrm{T}$ cells expressing DR5, transforming $\mathrm{pDC}$ into Interferon-producing Killer pDC (IKpDC) [86]. Interaction of HTLV-1 SU binding and NRP-1 in infected cells might by itself disturb DC-T cells interactions, and thus impair the immune response. This is consistent with previous reports that soluble HTLV-1 SU has an inhibitory effect on a mixed lymphocyte reaction [22]. This phenomenon might be of particular significance during primary infection when there is an active transcription of viral products including Env, which could thus dampen the primary antiviral response. Alternatively, IKpDC may reduce spreading of infection by killing infected $\mathrm{T}$ cells and allowing the emergence of few infected $\mathrm{T}$ cell clones in the infected host. Finally, infection of immature myDC might disturb $\mathrm{T}$ cell homeostasis and lead to an increased risk of autoimmune phenomena.

\section{Potential effects of NRP-1 ligands VEGFA $_{165}$}

Data clearly show that VEGFA VI65 $_{16}$ is a potent competitor of HTLV-1 SU binding and HTLV-1 infection of primary $\mathrm{T}$ cells and DC in vitro [4,72]. VEGFA 165 secretion by HTLV-1-infected cells [87] might explain the phenomenon of receptor interference. By preventing the generalised spreading of the virus, it might also explain the peculiar course of HTLV-1 infection in which a limited number of $\mathrm{T}$ cell clones are infected following primary infection. Because it increases NRP-1 expression at the surface of target cells [88], VEGFA 165 might not only have a negative effect. Sherer et al. showed in an elegant model of MLV infection that target cells projected filopodiae towards MLV infected cells [89]. These expansions, which the authors termed viral cytonemes, create an intercellular bridge that allows the virus to "slide" towards its target cell and bind to its receptor. Endothelial cells, which have been found to be infected in vivo [25] and coexpress NRP-1 and VEGFR2, are able to project similar cytoplasmic expansions, or filopodiae, towards VEGFA 165 [90]. Although the relevance of this phenomenon in other retroviral infections remains to be studied, a similar mechanism driven by the interaction between NRP-1 and either VEGFA 165 or Env itself might be envisaged with HTLV-1.

In ATLL it has been shown that VEGFA 165 production may participate in cell growth and angiogenesis $[91,92]$. At this stage of the disease, the NRP-1/ VEGFA $_{165}$ interaction may occur because the virus Env is no longer expressed in vivo.

\section{Semaphorin-3a}

Another major NRP-1 ligand, sema3a, could also play a role in the regulation of $\mathrm{HTLV}-1$ infection. Polarization of the cytoskeleton is a critical determinant of transmission in a number of retroviruses including HIV-1 and HTLV-1 [75]. Although Tax has been shown to accumulate at the cell-cell junction and be involved in the microtubule reorganization [84], little is known about the precise mechanisms responsible for this phenomenon. In the central nervous system, sema3a blocks Factin polymerization, which results in the repulsion of the axon growth cone [93]. In the immune system, sema3a-NRP-1 interactions inhibit the cytoskeletal polarization following the contact between a DC and a $\mathrm{T}$ cell [74]. This process may provide the negative feedback cues to disorganize the immune synapse, allowing $\mathrm{T}$ cells to migrate from DC. In HTLV-1 infection, sema3a could play a negative role by inhibiting the cytoskeletal rearrangement that is necessary for HTLV-1 entry. Thus, interaction between the Env and NRP-1 may prevent the action of Sema3A on the activated $\mathrm{T}$ cell target, thus allowing HTLV-1 infection.

\section{Conclusion}

The recent discovery that GLUT1, NRP-1 and HSPG are involved in HTLV-1 entry sheds new light on HTLV-1 infection and the physiopathology of HTLV-1-related diseases. The demonstration that HTLV-1 uses molecules involved in the immune response and can infect dendritic cells more efficiently than $\mathrm{CD}^{+} \mathrm{T}$ cells provides fascinating perspectives for future research. Further work is clearly needed to better define the precise role of the elements of this "ménage à trois" and its consequence on infected individuals. A better understanding of the effect of HTLV-1 infection on the 
immune system could lead to the development of alternative strategies in the treatment of HTLV-1-related diseases early in the course of the infection or even at a later stage, as in ATLL.

\section{Acknowledgements}

The authors would like to thank the French Foundation "Cent pour sang la Vie", Institut National du cancer (INCA), Association de lutte contre le cancer, ligue nationale contre le cancer, cancéropole d'ile de France, foundation pour la recherche médicale, foundation de France for the financial support of this work.

\section{Author details}

'CNRS UMR8147, Universite Rene Descartes, Paris 5, 161 Rue de Sèvres, 75743 Paris Cedex 15, France. ${ }^{2}$ Service d'Hématologie, Institut Gustave Roussy, 39 rue Camille Desmoulins 94805 Villejuif, France. ${ }^{3}$ SAIC-Frederick, Inc., NCl-Frederick, Frederick, MD, USA. ${ }^{4}$ Institut Cochin, Université Paris Descartes, CNRS (UMR 8104), Paris, France. Inserm, U1016, Paris, France. ${ }^{6}$ Service d'Hématologie Adulte, Hôpital Necker, 161 Rue de Sèvres, 75743 Paris CEDEX 15, France.

\section{Authors' contributions}

$\mathrm{OH}$ and DG designed the manuscript. DG wrote the manuscript. YL, KSJ, CP revised and added new information to the manuscript. $\mathrm{OH}$ coordinated the work and finalized the manuscript with DG.

\section{Competing interests}

The authors declare that they have no competing interests.

Received: 24 April 2010 Accepted: 29 November 2010 Published: 29 November 2010

\section{References}

1. Jin Q, Agrawal L, VanHorn-Ali Z, Alkhatib G: Infection of CD4+ T lymphocytes by the human $T$ cell leukemia virus type 1 is mediated by the glucose transporter GLUT-1: evidence using antibodies specific to the receptor's large extracellular domain. Virology 2006, 349:184-196.

2. Manel N, Kim FJ, Kinet S, Taylor N, Sitbon M, Battini JL: The ubiquitous glucose transporter GLUT-1 is a receptor for HTLV. Cell 2003, 115:449-459.

3. Jin Q, Alkhatib B, Cornetta K, Alkhatib G: Alternate receptor usage of neuropilin-1 and glucose transporter protein 1 by the human $T$ cell leukemia virus type 1. Virology 2009, 396:203-212.

4. Lambert S, Bouttier M, Vassy R, Seigneuret M, Petrow-Sadowski C, Janvier S, Heveker N, Ruscetti FW, Perret G, Jones KS, Pique C: HTLV-1 uses HSPG and neuropilin-1 for entry by molecular mimicry of VEGF165. Blood 2009, 113:5176-5185.

5. Ghez D, Lepelletier $Y$, Lambert $S$, Fourneau JM, Blot $V$, Janvier $S$, Arnulf $B$, van Endert PM, Heveker N, Pique C, Hermine O: Neuropilin-1 is involved in human T-cell lymphotropic virus type 1 entry. J Virol 2006, 80:6844-6854.

6. Jones KS, Petrow-Sadowski C, Bertolette DC, Huang Y, Ruscetti FW: Heparan sulfate proteoglycans mediate attachment and entry of human T-cell leukemia virus type 1 virions into CD4+ T cells. J Virol 2005, 79:12692-12702.

7. Pinon JD, Klasse PJ, Jassal SR, Welson S, Weber J, Brighty DW, Sattentau QJ: Human T-cell leukemia virus type 1 envelope glycoprotein gp46 interacts with cell surface heparan sulfate proteoglycans. J Virol 2003, 77:9922-9930.

8. Delamarre L, Rosenberg AR, Pique C, Pham D, Callebaut I, Dokhelar MC The HTLV-I envelope glycoproteins: structure and functions. J Acquir Immune Defic Syndr Hum Retrovirol 1996, 13(Suppl 1):S85-91.

9. Wyatt R, Sodroski J: The HIV-1 envelope glycoproteins: fusogens, antigens, and immunogens. Science 1998, 280:1884-1888.

10. Kobe B, Center RJ, Kemp BE, Poumbourios P: Crystal structure of human T cell leukemia virus type $1 \mathrm{gp} 21$ ectodomain crystallized as a maltosebinding protein chimera reveals structural evolution of retroviral transmembrane proteins. Proc Natl Acad Sci USA 1999, 96:4319-4324

11. Maerz AL, Center RJ, Kemp BE, Kobe B, Poumbourios P: Functional implications of the human T-lymphotropic virus type 1 transmembrane glycoprotein helical hairpin structure. J Virol 2000, 74:6614-6621.
12. Delamarre L, Pique C, Pham D, Tursz T, Dokhelar MC: Identification of functional regions in the human T-cell leukemia virus type I SU glycoprotein. J Virol 1994, 68:3544-3549.

13. Pique C, Tursz T, Dokhelar MC: Mutations introduced along the HTLV-I envelope gene result in a non-functional protein: a basis for envelope conservation? Embo J 1990, 9:4243-4248.

14. Jassal SR, Lairmore MD, Leigh-Brown AJ, Brighty DW: Soluble recombinant HTLV-1 surface glycoprotein competitively inhibits syncytia formation and viral infection of cells. Virus Res 2001, 78:17-34.

15. Li K, Zhang S, Kronqvist M, Wallin M, Ekstrom M, Derse D, Garoff H: Intersubunit disulfide isomerization controls membrane fusion of human T-cell leukemia virus Env. J Virol 2008, 82:7135-7143.

16. Sommerfelt MA: Retrovirus receptors. J Gen Virol 1999, 80(Pt 12):3049-3064.

17. Fan N, Gavalchin J, Paul B, Wells KH, Lane MJ, Poiesz BJ: Infection of peripheral blood mononuclear cells and cell lines by cell-free human Tcell lymphoma/leukemia virus type I. J Clin Microbiol 1992, 30:905-910.

18. Derse D, Hill SA, Lloyd PA, Chung H, Morse BA: Examining human Tlymphotropic virus type 1 infection and replication by cell-free infection with recombinant virus vectors. J Virol 2001, 75:8461-8468.

19. Richardson JH, Edwards AJ, Cruickshank JK, Rudge P, Dalgleish AG: In vivo cellular tropism of human T-cell leukemia virus type 1. J Virol 1990, 64:5682-5687.

20. Hanon E, Stinchcombe JC, Saito M, Asquith BE, Taylor GP, Tanaka Y, Weber JN, Griffiths GM, Bangham CR: Fratricide among CD8(+) T lymphocytes naturally infected with human $T$ cell lymphotropic virus type I. Immunity 2000, 13:657-664

21. Koyanagi Y, Itoyama Y, Nakamura N, Takamatsu K, Kira J, Iwamasa T, Goto I, Yamamoto N: In vivo infection of human T-cell leukemia virus type I in non-T cells. Virology 1993, 196:25-33.

22. Nath MD, Ruscetti FW, Petrow-Sadowski C, Jones KS: Regulation of the cell-surface expression of an HTLV-I binding protein in human T cells during immune activation. Blood 2003, 101:3085-3092.

23. Knight SC, Macatonia SE, Cruickshank K, Rudge P, Patterson S: Dendritic cells in HIV-1 and HTLV-1 infection. Adv Exp Med Biol 1993, 329:545-549.

24. Macatonia SE, Cruickshank JK, Rudge P, Knight SC: Dendritic cells from patients with tropical spastic paraparesis are infected with HTLV-1 and stimulate autologous lymphocyte proliferation. AIDS Res Hum Retroviruses 1992, 8:1699-1706.

25. Setoyama M, Kerdel FA, Elgart G, Kanzaki T, Byrnes JJ: Detection of HTLV-1 by polymerase chain reaction in situ hybridization in adult $\mathrm{T}$-cell leukemia/lymphoma. Am J Pathol 1998, 152:683-689.

26. Suzuki M, Matsuoka H, Yamashita K, Maeda K, Kawano K, Uno H, Tsubouchi H: CD45RO expression on peripheral lymphocytes as a prognostic marker for adult T-cell leukemia. Leuk Lymphoma 1998 28:583-590.

27. Ruben S, Poteat H, Tan TH, Kawakami K, Roeder R, Haseltine W, Rosen CA: Cellular transcription factors and regulation of IL-2 receptor gene expression by HTLV-I tax gene product. Science 1988, 241:89-92.

28. Yamano Y, Takenouchi N, Li HC, Tomaru U, Yao K, Grant CW, Maric DA, Jacobson S: Virus-induced dysfunction of $\mathrm{CD} 4+\mathrm{CD} 25+\mathrm{T}$ cells in patients with HTLV-I-associated neuroimmunological disease. J Clin Invest 2005, 115:1361-1368

29. Lohr J, Knoechel B, Abbas AK: Regulatory T cells in the periphery. Immunol Rev 2006, 212:149-162.

30. Toulza F, Nosaka K, Takiguchi M, Pagliuca T, Mitsuya H, Tanaka Y, Taylor GP, Bangham CR: FoxP3+ regulatory T cells are distinct from leukemia cells in HTLV-1-associated adult T-cell leukemia. Int I Cancer 2009, 125:2375-2382.

31. Abe M, Uchihashi K, Kazuto T, Osaka A, Yanagihara K, Tsukasaki K, Hasegawa H, Yamada Y, Kamihira S: Foxp3 expression on normal and leukemic CD4+CD25+ T cells implicated in human T-cell leukemia virus type-1 is inconsistent with Treg cells. Eur J Haematol 2008, 81:209-217.

32. Yano $H$, Ishida $T$, Inagaki A, Ishii T, Kusumoto $S$, Komatsu $H$, lida $S$, Utsunomiya A, Ueda R: Regulatory T-cell function of adult T-cell leukemia/lymphoma cells. Int J Cancer 2007, 120:2052-2057.

33. Chen S, Ishii N, Ine S, Ikeda S, Fujimura T, Ndhlovu LC, Soroosh P, Tada K, Harigae H, Kameoka J, Kasai N, Sasaki T, Sugamura K: Regulatory T cell-like activity of Foxp3+ adult T cell leukemia cells. Int Immunol 2006, 18:269-277.

34. Grant C, Oh U, Yao K, Yamano Y, Jacobson S: Dysregulation of TGF-beta signaling and regulatory and effector T-cell function in virus-induced neuroinflammatory disease. Blood 2008, 111:5601-5609. 
35. Toulza F, Heaps A, Tanaka Y, Taylor GP, Bangham CR: High frequency of CD4+FoxP3+ cells in HTLV-1 infection: inverse correlation with HTLV-1specific CTL response. Blood 2008, 111:5047-5053.

36. Trejo SR, Ratner L: The HTLV receptor is a widely expressed protein. Virology 2000, 268:41-48.

37. Okuma K, Nakamura M, Nakano S, Niho Y, Matsuura Y: Host range of human T-cell leukemia virus type I analyzed by a cell fusion-dependent reporter gene activation assay. Virology 1999, 254:235-244.

38. Sutton RE, Littman DR: Broad host range of human T-cell leukemia virus type 1 demonstrated with an improved pseudotyping system. J Virol 1996, 70:7322-7326.

39. Jassal SR, Pohler RG, Brighty DW: Human T-cell leukemia virus type 1 receptor expression among syncytium-resistant cell lines revealed by a novel surface glycoprotein-immunoadhesin. J Virol 2001, 75:8317-8328.

40. Manel N, Kinet S, Battini JL, Kim FJ, Taylor N, Sitbon M: The HTLV receptor is an early T-cell activation marker whose expression requires de novo protein synthesis. Blood 2003, 101:1913-1918.

41. Jones KS, Akel S, Petrow-Sadowski C, Huang Y, Bertolette DC, Ruscetti FW: Induction of human $T$ cell leukemia virus type I receptors on quiescent naive T lymphocytes by TGF-beta. J Immunol 2005, 174:4262-4270.

42. Moriuchi M, Moriuchi H: Transforming growth factor-beta enhances human T-cell leukemia virus type I infection. J Med Virol 2002, 67:427-430.

43. Sommerfelt MA, Williams BP, Clapham PR, Solomon E, Goodfellow PN, Weiss RA: Human T cell leukemia viruses use a receptor determined by human chromosome 17. Science 1988, 242:1557-1559.

44. Agadjanyan MG, Chattergoon MA, Petrushina I, Bennett M, Kim J, Ugen KE, Kieber-Emmons T, Weiner DB: Monoclonal antibodies define a cellular antigen involved in HTLV-I infection. Hybridoma 1998, 17:9-19.

45. Imai T, Fukudome K, Takagi S, Nagira M, Furuse M, Fukuhara N, Nishimura M, Hinuma $Y$, Yoshie O: C33 antigen recognized by monoclonal antibodies inhibitory to human $T$ cell leukemia virus type 1 -induced syncytium formation is a member of a new family of transmembrane proteins including CD9, CD37, CD53, and CD63. J Immunol 1992, 149:2879-2886.

46. Imai $\mathrm{T}$, Yoshie $\mathrm{O}$ : C33 antigen and M38 antigen recognized by monoclonal antibodies inhibitory to syncytium formation by human $\mathrm{T}$ cell leukemia virus type 1 are both members of the transmembrane 4 superfamily and associate with each other and with CD4 or CD8 in T cells. J Immunol 1993, 151:6470-6481.

47. Hildreth JE: Syncytium-inhibiting monoclonal antibodies produced against human T-cell lymphotropic virus type 1-infected cells recognize class II major histocompatibility complex molecules and block by protein crowding. J Virol 1998, 72:9544-9552.

48. Daenke S, McCracken SA, Booth S: Human T-cell leukaemia/lymphoma virus type 1 syncytium formation is regulated in a cell-specific manner by ICAM-1, ICAM-3 and VCAM-1 and can be inhibited by antibodies to integrin beta2 or beta7. J Gen Virol 1999, 80(Pt 6):1429-1436.

49. Sagara $Y$, Ishida $C$, Inoue $Y$, Shiraki H, Maeda $Y$ : 71-kilodalton heat shock cognate protein acts as a cellular receptor for syncytium formation induced by human T-cell lymphotropic virus type 1. J Virol 1998, 72:535-541.

50. Fang D, Haraguchi $Y$, Jinno A, Soda $Y$, Shimizu N, Hoshino $H$ : Heat shock cognate protein 70 is a cell fusion-enhancing factor but not an entry factor for human T-cell lymphotropic virus type I. Biochem Biophys Res Commun 1999, 261:357-363.

51. Pique C, Lagaudriere-Gesbert C, Delamarre L, Rosenberg AR, Conjeaud H, Dokhelar MC: Interaction of CD82 tetraspanin proteins with HTLV-1 envelope glycoproteins inhibits cell-to-cell fusion and virus transmission. Virology 2000, 276:455-465.

52. Kim FJ, Manel N, Garrido EN, Valle C, Sitbon M, Battini JL: HTLV-1 and -2 envelope SU subdomains and critical determinants in receptor binding. Retrovirology 2004, 1:41.

53. Kim FJ, Seiliez I, Denesvre C, Lavillette D, Cosset FL, Sitbon M: Definition of an amino-terminal domain of the human T-cell leukemia virus type 1 envelope surface unit that extends the fusogenic range of an ecotropic murine leukemia virus. J Biol Chem 2000, 275:23417-23420.

54. Manel N, Battini JL, Sitbon M: Human T cell leukemia virus envelope binding and virus entry are mediated by distinct domains of the glucose transporter GLUT1. J Biol Chem 2005, 280:29025-29029.
55. Coskun AK, Sutton RE: Expression of glucose transporter 1 confers susceptibility to human T-cell leukemia virus envelope-mediated fusion. J Virol 2005, 79:4150-4158.

56. Jin Q, Agrawal L, Vanhorn-Ali Z, Alkhatib G: GLUT-1-independent infection of the glioblastoma/astroglioma U87 cells by the human T cell leukemia virus type 1. Virology 2006, 353:99-110.

57. Takenouchi N, Jones KS, Lisinski I, Fugo K, Yao K, Cushman SW, Ruscetti FW, Jacobson S: GLUT1 is not the primary binding receptor but is associated with cell-to-cell transmission of human T-cell leukemia virus type 1. Virol 2007, 81:1506-1510.

58. Jones KS, Huang YK, Chevalier SA, Afonso PV, Petrow-Sadowski C, Bertolette DC, Gessain A, Ruscetti FW, Mahieux R: The receptor complex associated with human T-cell lymphotropic virus type 3 (HTLV-3) Envmediated binding and entry is distinct from, but overlaps with, the receptor complexes of HTLV-1 and HTLV-2. J Virol 2009, 83:5244-5255.

59. Bishop JR, Schuksz M, Esko JD: Heparan sulphate proteoglycans fine-tune mammalian physiology. Nature 2007, 446:1030-1037.

60. Vives RR, Lortat-Jacob H, Fender P: Heparan sulphate proteoglycans and viral vectors: ally or foe? Curr Gene Ther 2006, 6:35-44.

61. Mondor I, Ugolini S, Sattentau QJ: Human immunodeficiency virus type 1 attachment to HeLa CD4 cells is CD4 independent and gp120 dependent and requires cell surface heparans. J Virol 1998, 72:3623-3634.

62. Shukla D, Liu J, Blaiklock P, Shworak NW, Bai X, Esko JD, Cohen GH, Eisenberg RJ, Rosenberg RD, Spear PG: A novel role for 3-O-sulfated heparan sulfate in herpes simplex virus 1 entry. Cell 1999, 99:13-22.

63. Ibrahim J, Griffin P, Coombe DR, Rider CC, James W: Cell-surface heparan sulfate facilitates human immunodeficiency virus Type 1 entry into some cell lines but not primary lymphocytes. Virus Res 1999, 60:159-169.

64. Pais-Correia AM, Sachse M, Guadagnini S, Robbiati V, Lasserre R, Gessain A, Gout O, Alcover A, Thoulouze MI: Biofilm-like extracellular viral assemblies mediate HTLV-1 cell-to-cell transmission at virological synapses. Nat Med 2009, 16:83-89.

65. Gauthier S, Pelletier I, Ouellet M, Vargas A, Tremblay MJ, Sato S, Barbeau B: Induction of galectin-1 expression by HTLV-I Tax and its impact on HTLV-I infectivity. Retrovirology 2008, 5:105.

66. Jones KS, Fugo K, Petrow-Sadowski C, Huang Y, Bertolette DC, Lisinski I, Cushman SW, Jacobson S, Ruscetti FW: Human T-cell leukemia virus type 1 (HTLV-1) and HTLV-2 use different receptor complexes to enter T cells. J Virol 2006, 80:8291-8302.

67. Sommerfelt MA, Weiss RA: Receptor interference groups of 20 retroviruses plating on human cells. Virology 1990, 176:58-69.

68. Xie L, Green PL: Envelope is a major viral determinant of the distinct in vitro cellular transformation tropism of human T-cell leukemia virus type 1 (HTLV-1) and HTLV-2. J Virol 2005, 79:14536-14545.

69. Reeves JD, Hibbitts S, Simmons G, McKnight A, Azevedo-Pereira JM, MonizPereira J, Clapham PR: Primary human immunodeficiency virus type 2 (HIV-2) isolates infect CD4-negative cells via CCR5 and CXCR4: comparison with HIV-1 and simian immunodeficiency virus and relevance to cell tropism in vivo. J Virol 1999, 73:7795-7804.

70. Tordjman R, Lepelletier Y, Lemarchandel V, Cambot M, Gaulard P, Hermine O, Romeo PH: A neuronal receptor, neuropilin-1, is essential for the initiation of the primary immune response. Nat Immunol 2002, 3:477-482.

71. Ellis LM: The role of neuropilins in cancer. Mol Cancer Ther 2006, 5:1099-1107.

72. Jones KS, Petrow-Sadowski C, Huang YK, Bertolette DC, Ruscetti FW: Cellfree HTLV-1 infects dendritic cells leading to transmission and transformation of CD4(+) T cells. Nat Med 2008, 14:429-436.

73. Soker S, Takashima S, Miao HQ, Neufeld G, Klagsbrun M: Neuropilin-1 is expressed by endothelial and tumor cells as an isoform-specific receptor for vascular endothelial growth factor. Cell 1998, 92:735-745.

74. Lepelletier Y, Moura IC, Hadj-Slimane R, Renand A, Fiorentino S, Baude C, Shirvan A, Barzilai A, Hermine O: Immunosuppressive role of semaphorin$3 \mathrm{~A}$ on $\mathrm{T}$ cell proliferation is mediated by inhibition of actin cytoskeleton reorganization. Eur J Immunol 2006, 36:1782-1793.

75. Igakura T, Stinchcombe JC, Goon PK, Taylor GP, Weber JN, Griffiths GM, Tanaka Y, Osame M, Bangham CR: Spread of HTLV-I between lymphocytes by virus-induced polarization of the cytoskeleton. Science 2003, 299:1713-1716.

76. Crublet $E$, Andrieu JP, Vives RR, Lortat-Jacob H: The HIV-1 envelope glycoprotein gp120 features four heparan sulfate binding domains, 
including the co-receptor binding site. J Biol Chem 2008, 283:15193-15200.

77. Vander Kooi CW, Jusino MA, Perman B, Neau DB, Bellamy HD, Leahy DJ: Structural basis for ligand and heparin binding to neuropilin B domains. Proc Natl Acad Sci USA 2007, 104:6152-6157.

78. Palker TJ, Riggs ER, Spragion DE, Muir AJ, Scearce RM, Randall RR, McAdams MW, McKnight A, Clapham PR, Weiss RA, et al: Mapping of homologous, amino-terminal neutralizing regions of human T-cell lymphotropic virus type I and II gp46 envelope glycoproteins. J Virol 1992, 66:5879-5889.

79. Chanel C, Staropoli I, Baleux F, Amara A, Valenzuela-Fernandez A, Virelizier JL, Arenzana-Seisdedos F, Altmeyer R: Low levels of co-receptor CCR5 are sufficient to permit HIV envelope-mediated fusion with resting CD4 T cells. Aids 2002, 16:2337-2340.

80. Bunn RC, Jensen MA, Reed BC: Protein interactions with the glucose transporter binding protein GLUT1CBP that provide a link between GLUT1 and the cytoskeleton. Mol Biol Cell 1999, 10:819-832.

81. Cai H, Reed RR: Cloning and characterization of neuropilin-1-interacting protein: a PSD-95/Dlg/ZO-1 domain-containing protein that interacts with the cytoplasmic domain of neuropilin-1. J Neurosci 1999, 19:6519-6527.

82. Grootjans JJ, Zimmermann P, Reekmans G, Smets A, Degeest G, Durr J, David G: Syntenin, a PDZ protein that binds syndecan cytoplasmic domains. Proc Natl Acad Sci USA 1997, 94:13683-13688.

83. Yoshida S, Higuchi M, Shoji T, Yoshita M, Ishioka K, Takahashi M, Oie M, Tanaka Y, Uchiyama M, Fujii M: Knockdown of synapse-associated protein Dlg1 reduces syncytium formation induced by human T-cell leukemia virus type 1. Virus Genes 2008, 37:9-15.

84. Azakami K, Sato T, Araya N, Utsunomiya A, Kubota R, Suzuki K, Hasegawa D, Izumi T, Fujita H, Aratani S, Fujii R, Yagishita N, Kamijuku H, Kanekura T, Seino K, Nishioka K, Nakajima T, Yamano Y: Severe loss of invariant NKT cells exhibiting anti-HTLV-1 activity in patients with HTLV-1-associated disorders. Blood 2009 114:3208-15.

85. Hishizawa M, Imada K, Kitawaki T, Ueda M, Kadowaki N, Uchiyama T Depletion and impaired interferon-alpha-producing capacity of blood plasmacytoid dendritic cells in human T-cell leukaemia virus type Iinfected individuals. Br J Haematol 2004, 125:568-575.

86. Colisson R, Barblu L, Gras C, Raynaud F, Hadj-Slimane R, Pique C, Hermine O, Lepelletier Y, Herbeuval JP: Free HTLV-1 induces TLR7dependent innate immune response and TRAIL relocalization in killer plasmacytoid dendritic cells. Blood 2009, 115:2177-2185.

87. El-Sabban ME, Merhi RA, Haidar HA, Arnulf B, Khoury H, Basbous J, Nijmeh J, de The $\mathrm{H}$, Hermine $\mathrm{O}$, Bazarbachi A: Human T-cell lymphotropic virus type 1-transformed cells induce angiogenesis and establish functional gap junctions with endothelial cells. Blood 2002, 99:3383-3389.

88. Oh H, Takagi H, Otani A, Koyama S, Kemmochi S, Uemura A, Honda Y: Selective induction of neuropilin-1 by vascular endothelial growth factor (VEGF): a mechanism contributing to VEGF-induced angiogenesis. Proc Natl Acad Sci USA 2002, 99:383-388.

89. Sherer NM, Lehmann MJ, Jimenez-Soto LF, Horensavitz C, Pypaert M, Mothes W: Retroviruses can establish filopodial bridges for efficient cellto-cell transmission. Nat Cell Biol 2007, 9:310-315.

90. Ruhrberg C, Gerhardt H, Golding M, Watson R, loannidou S, Fujisawa H, Betsholtz C, Shima DT: Spatially restricted patterning cues provided by heparin-binding VEGF-A control blood vessel branching morphogenesis. Genes Dev 2002, 16:2684-2698.

91. Bazarbachi A, Abou Merhi R, Gessain A, Talhouk R, El-Khoury H, Nasr R, Gout O, Sulahian R, Homaidan F, de Thé H, Hermine O, El-Sabban ME: Human T-cell lymphotropic virus type I-infected cells extravasate through the endothelial barrier by a local angiogenesis-like mechanism. Cancer Res 2004, 15:2039-46.

92. El-Sabban ME, Merhi RA, Haidar HA, Arnulf B, Khoury H, Basbous J, Nijmeh J, de Thé $\mathrm{H}$, Hermine $\mathrm{O}$, Bazarbachi A: Human T-cell lymphotropic virus type 1-transformed cells induce angiogenesis and establish functional gap junctions with endothelial cells. Blood 2002, 99:3383-9.

93. Nakamura F, Tanaka M, Takahashi T, Kalb RG, Strittmatter SM: Neuropilin-1 extracellular domains mediate semaphorin D/III-induced growth cone collapse. Neuron 1998, 21:1093-1100.

doi:10.1186/1742-4690-7-99

Cite this article as: Ghez et al:: Current concepts regarding the HTLV-1 receptor complex. Retrovirology 2010 7:99.

\section{Submit your next manuscript to BioMed Central and take full advantage of:}

- Convenient online submission

- Thorough peer review

- No space constraints or color figure charges

- Immediate publication on acceptance

- Inclusion in PubMed, CAS, Scopus and Google Scholar

- Research which is freely available for redistribution

Submit your manuscript at www.biomedcentral.com/submit
C Biomed Central 